\title{
A novel preparation method for silicone oil nanoemulsions and its application for coating hair with silicone
}

This article was published in the following Dove Press journal:

International Journal of Nanomedicine

9 November 2012

Number of times this article has been viewed

\author{
Zhenhua $\mathrm{Hu}^{1,2, *}$ \\ Meiling Liao,* \\ Yinghui Chen ${ }^{3, *}$ \\ Yunpeng $\mathrm{Cai}^{2}$ \\ Lele Meng ${ }^{2}$ \\ Yajun Liu $^{2}$ \\ Nan Lv ${ }^{2}$ \\ Zhenguo Liu' \\ Weien Yuan ${ }^{2}$ \\ 'Department of Neurology, Xinhua \\ Hospital Affiliated to Shanghai Jiao \\ Tong University School of Medicine, \\ Shanghai, People's Republic of China; \\ ${ }^{2}$ School of Pharmacy, Shanghai Jiao \\ Tong University, Shanghai, People's \\ Republic of China; ${ }^{3}$ Department \\ of Neurology, Jinshan Hospital, Fudan \\ University, Jinshan District, Shanghai, \\ People's Republic of China \\ *These authors contributed equally \\ to this work
}

Background: Silicone oil, as a major component in conditioner, is beneficial in the moisture preservation and lubrication of hair. However, it is difficult for silicone oil to directly absorb on the hair surface because of its hydrophobicity. Stable nanoemulsions containing silicone oil may present as a potential solution to this problem.

Methods: Silicone oil nanoemulsions were prepared using the oil-in-water method with nonionic surfactants. Emulsion particle size and distribution were characterized by scanning electron microscopy. The kinetic stability of this nanoemulsion system was investigated under accelerated stability tests and long-term storage. The effect of silicone oil deposition on hair was examined by analyzing the element of hair after treatment of silicone oil nanoemulsions.

Results: Nonionic surfactants such as Span 80 and Tween 80 are suitable emulsifiers to prepare oil-in-water nanoemulsions that are both thermodynamically stable and can enhance the absorption of silicone oil on hair surface.

Conclusion: The silicone oil-in-water nanoemulsions containing nonionic surfactants present as a promising solution to improve the silicone oil deposition on the hair surface for hair care applications.

Keywords: silicone oil, nanoemulsion, stability, moisture preservation, lubrication

\section{Introduction}

Today's shampoo formulations go beyond the stage of pure cleansing of the hair. Additional benefits are expected, eg, conditioning, smoothing of the hair surface, improvement of compatibility, and lather creaminess. However, it is challenging to efficiently integrate both cleansing and conditioning functions into one shampoo formulation, because silicone oil, as a major component of general hair conditioner, is easily cleared away from the hair with accompanying greasy dirt during washing with shampoo. Procter and Gamble ([P\&G] Shanghai,China) has successfully solved this problem through exploring the interaction of cationic and anionic surfactants to achieve the deposition of silicone oil on hair. As yet, there are no other methods to overcome this issue. ${ }^{1-11}$

Hair fibers have a structure consisting of several layers. From the outside, they are the cuticle layer, hydrolipid emulsion layer, cortex layer, and medulla layer. ${ }^{1,2}$ The cuticle is composed of several layers of flat and thin cells laid out and overlapping one another like roof shingles. These hair scales are opened by hot water or alkali. The cortex layer contains keratin bundles in cell structures that are roughly rod-like. There is a continuous emulsion-like layer called the hydrolipid emulsion layer, which is between the cuticle and cortex layers and maintains the water in hair. Its permeability enables 
both the absorption of external water and the preservation of internal water. In addition, it can also improve the elasticity of hair and prevent the shedding of cuticles. ${ }^{12-15}$

During washing, the hair scales are opened, leading to the exposure of the internal hydrolipid emulsion layer and cortex layer, which renders the hair hydrophilic. However, the scalp and silicone oil are both hydrophobic, making silicone oil prone to accumulate on the scalp instead of on hair. To solve this problem, we have developed an oil-inwater nanoemulsion formulation using nonionic surfactant to deliver the silicone oil on the hair surface. Nanoemulsion is an oil-in-water dispersion system consisting of oil, water, and surfactant, frequently in combination with a cosurfactant. ${ }^{16-19}$ The particle size of the dispersed phase is in the range of 100-700 $\mathrm{nm}$. It is advantageous to prepare shampoos with this system because, firstly, nanoemulsion is a self-assembled thermodynamically stable system; thus, it can be easily produced, delivered, and preserved. Furthermore, it can be rapidly diffused into hair due to its small particle size. Last but not least, it can effectively combine both washing and hair care into one procedure, which saves time and effort.

For the choice of surfactants, the cationic surfactants are ruled out, as they are not typically used in shampoos, and the combination of cationic and anionic surfactants would cause the instability of emulsion. On the other hand, the anionic surfactants are not suitable either, because the same kind of surfactants in one shampoo would increase the repulsive force, which would make it difficult for silicone oil to stay on hair fibers. ${ }^{16-19}$ Therefore, the nonionic surfactants Span 80 and Tween 80 (Guangzhou Hanglian Chemical Industry Co, Ltd, Guangzhou, China) were chosen and combined to form a surfactant with a hydrophile-lipophile balance value close to that of the hydrolipid emulsion layer of hair. ${ }^{12-21}$ This property makes it a very desirable emulsifier to prepare oil-in-water nanoemulsion, because of its capability of fusing well with the hydrolipid emulsion layer to make hair glossier and healthier.

In this study, the preparation, characterization, and stability of the silicone oil-in-water nanoemulsion system is presented, and the effect of this system on improving silicone oil deposition on the hair surface is also discussed.

\section{Materials and methods}

\section{Preparation of silicone oil nanoemulsion}

Span 80, Tween 80, and n-butanol were first mixed by vortex to form an emulsifier phase, followed by adding dimethyl silicone oil as an oil phase, and mixing to make a uniform phase. Then, water was dropped into the mixture and stirred continuously. The change of the morphology of mixture was recorded. In addition, the three-phase diagram was described according to the compositions of the emulsion mixture.

\section{Measurement of particle sizes and zeta potential}

The mean droplet size, droplet size distribution, and zeta potential of freshly prepared nanoemulsions and nanoemulsions added into model shampoos and stored for different durations were measured by a laser particle analyzer (Mastersizer 2000, Malvern Instruments Ltd, Malvern, UK).

\section{Accelerating stability test for nanoemulsion}

In order to speed up the reactions to meet the requirements of products' shelf-lives, an accelerating stability test was performed by centrifuging $4 \mathrm{~mL}$ of the silicone oil nanoemulsion at $5000 \mathrm{rpm}$ for 10 minutes in a $5 \mathrm{~mL}$ centrifugal tube. ${ }^{14,15}$

\section{Cortex silicone elementary analysis}

Hair was immersed in silicone oil nanoemulsions and then measured by identification of peaks in an X-ray analysis system (EDS 2100) using a scanning electron microscope (JEOL, Tokyo, Japan) The accelerating voltage was set at $25 \mathrm{kV}$, the take-off angle was $25^{\circ}$, and the counting time was 60-100 live seconds. The samples were first impregnated with epoxy, followed by hardening and polishing using standard techniques for studying the cross-section.

\section{Results and discussion}

Schematic diagram of emulsion absorption by hydrolipid emulsion layer of hair

Figure 1 shows the structure of hair and the mechanism of nanoemulsion absorption to hair by hydrolipid emulsion layer. The similarity between properties (eg, hydrophile-lipophile balance) of nanoemulsion and the hydrolipid emulsion layer facilitated the absorption of nanoemulsion into hair.

\section{Pseudo three-phase diagram of nanoemulsion}

A pseudo three-phase diagram of nanoemulsion composed of water, silicone oil, and emulsifier was developed (Figure 2). The emulsifier was a mixture of Span 80 and Tween 80, and the auxiliary emulsifier was n-butanol. 
A

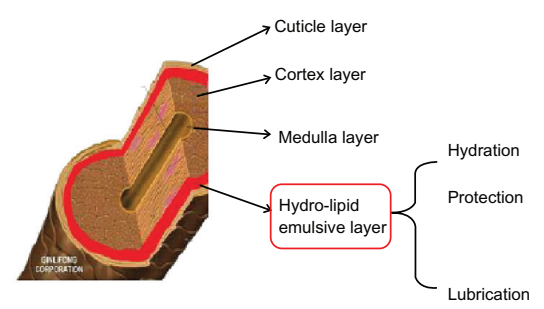

B

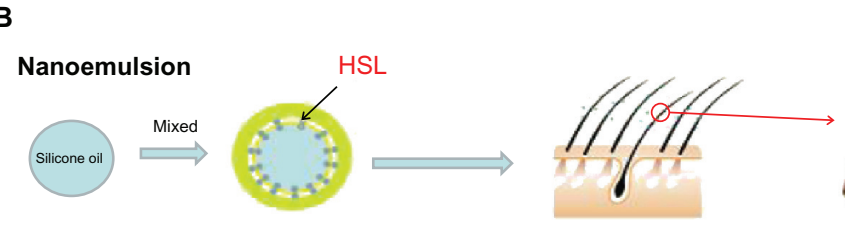

Nanoemulsion $\varnothing=150 \mathrm{~nm}$ electrically neutral
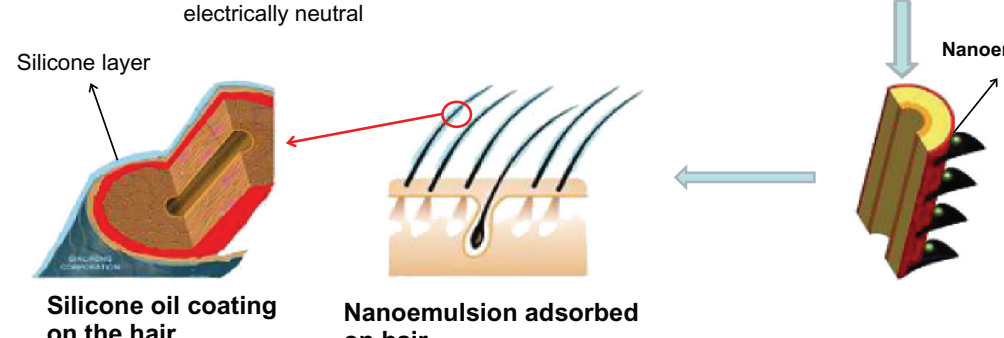
on the hair

Nanoemulsion adsorbed on hair

Figure I Schematic illustration of the process of nanoemulsion absorption to the hydrolipid emulsion layer of hair. (A) The internal structure of hair. (B) Nanoemulsion absorption to the hydrolipid emulsion layer of hair.

Abbreviation: HSL, Hydroxylated soybean lecithin.

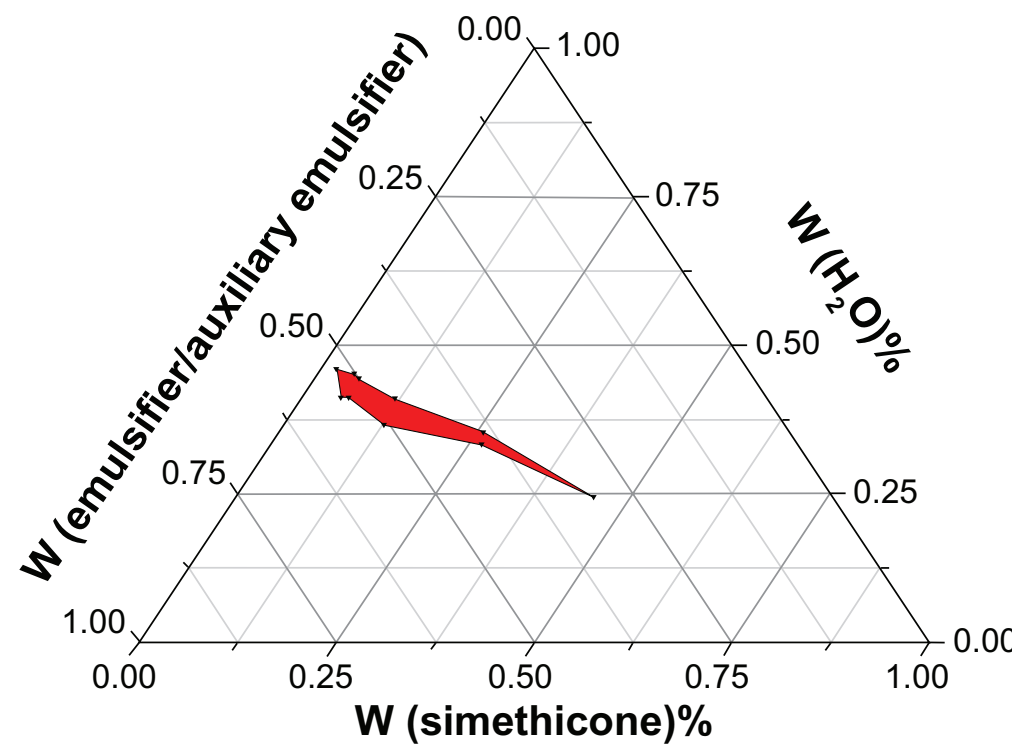

Figure 2 Pseudo three-phase diagram of nanoemulsion consisting of a water phase, an oil phase, and an emulsifier phase.

Table I The composition of selected oil-in-water nanoemulsion formulations

\begin{tabular}{|c|c|c|c|c|c|c|c|c|c|}
\hline Formulation & No I & No 2 & No 3 & No 4 & No 5 & No 6 & No 7 & No 8 & No 9 \\
\hline Dimethyl silicone oil (g) & 0.171 & 0.2 & 0.4 & 0.8 & 1 & 1.2 & 1.4 & 1.6 & 1.8 \\
\hline n-butanol $(\mathrm{g})$ & 0.464 & 0.45 & 0.4 & 0.3 & 0.25 & 0 & 0.15 & 0.1 & 0.05 \\
\hline Span $80(g)$ & 0.6825 & 0.675 & 0.6 & 0.45 & 0.25 & 0.3 & 0.225 & 0.15 & 0.075 \\
\hline Tween 80 (g) & 0.6825 & 0.675 & 0.6 & 0.45 & 0.38 & 0.3 & 0.225 & 0.15 & 0.075 \\
\hline Water (g) & $1.4-1.65$ & $1.4-1.6$ & I.15-1.4 & $1.0-1.1$ & 0.96 & 0.65 & & & \\
\hline
\end{tabular}




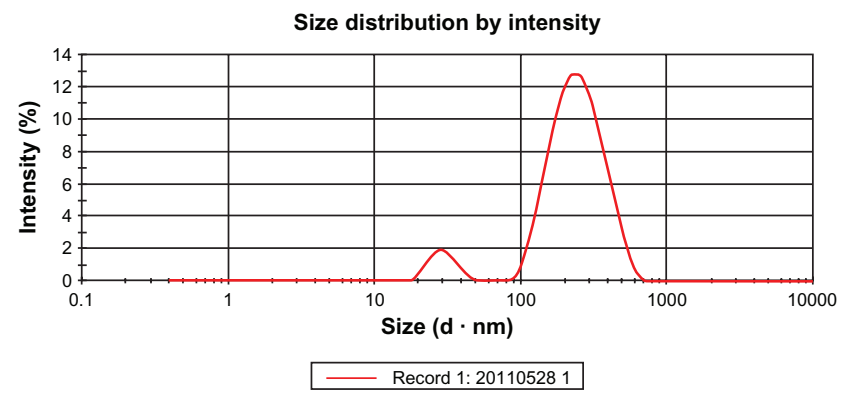

Figure 3 The size distribution of nanoemulsion droplets.

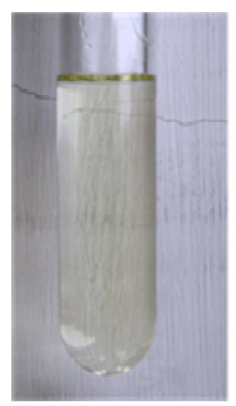

A

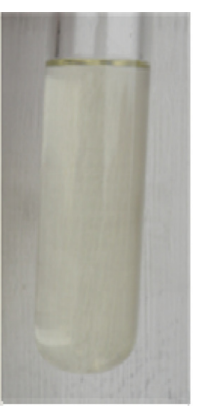

B

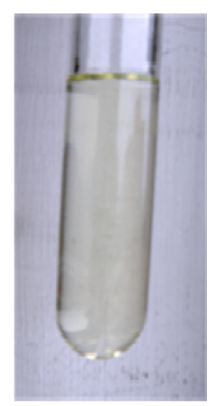

C
Figure 4 Optical microscope images of nanoemulsion. (A) The original nanoemulsion (B) After centrifugation at $3000 \mathrm{rpm}$ for 5 minutes. (C) After incubation at $40^{\circ} \mathrm{C}$ for 30 days.

Notes: Particle size $(\mathrm{nm}): 300 \pm 100,310 \pm 110$, and $315 \pm 113$. Zeta potential: $-17.6 \pm 4.3 \mathrm{mV},-16.6 \pm 6.2 \mathrm{mV}$, and $-16.2 \pm 6.5 \mathrm{mV}$.

Table 2 Average particle size and zeta potential of emulsion $(\mathrm{n}=3)$

\begin{tabular}{|c|c|c|c|}
\hline $\begin{array}{l}\text { Particle size } \\
(\mathrm{nm}) \text { (w/o } \\
\text { incubation } \\
\text { at } 40^{\circ} \mathrm{C} \text { for } \\
30 \text { days) }\end{array}$ & $\begin{array}{l}\text { Zeta potential } \\
\text { (w/o incubation } \\
\text { at } 40^{\circ} \mathrm{C} \text { for } \\
30 \text { days) }\end{array}$ & $\begin{array}{l}\text { Particle size } \\
(\mathrm{nm}) \text { (after } \\
\text { incubation } \\
\text { at } 40^{\circ} \mathrm{C} \text { for } \\
30 \text { days) }\end{array}$ & $\begin{array}{l}\text { Zeta potential } \\
\text { (after incubation } \\
\text { at } 40^{\circ} \mathrm{C} \text { for } \\
30 \text { days) }\end{array}$ \\
\hline $4000 \pm 463$ & $-5.7 \pm 2.1 \mathrm{mV}$ & $6310 \pm 1063$ & $-3.7 \pm 2.1 \mathrm{mV}$ \\
\hline $2000 \pm 204$ & $-6.3 \pm 2.3 \mathrm{mV}$ & $3220 \pm 504$ & $-5.3 \pm 2.3 \mathrm{mV}$ \\
\hline $300 \pm 100$ & $-17.6 \pm 4.3 \mathrm{mV}$ & $315 \pm 113$ & $-16.2 \pm 6.5 \mathrm{mV}$ \\
\hline
\end{tabular}
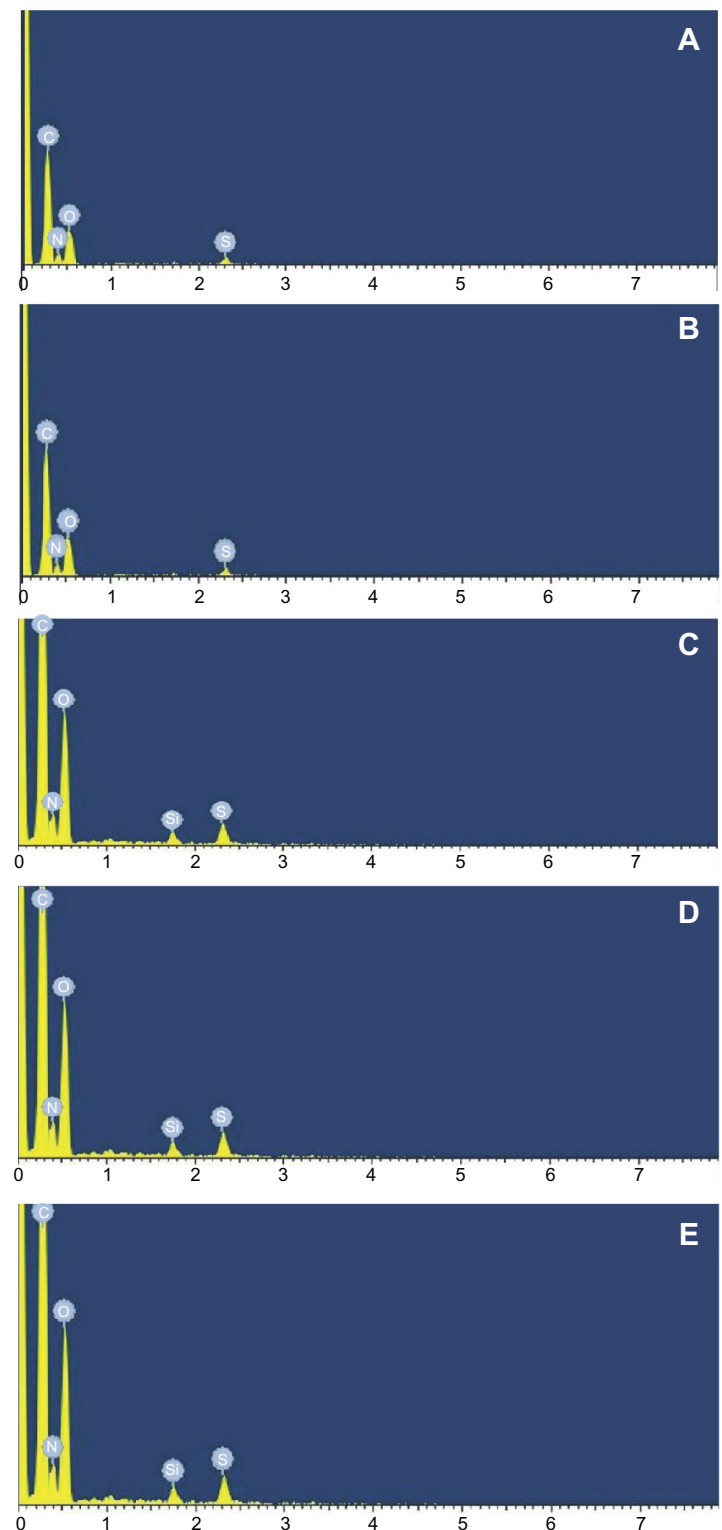

Figure 5 Element analysis of hair using the nanoemulsion. (A) Hair without treatment. (B) Hair with treatment of shampoos. (C) Hair with treatment of nanoemulsion $(4.0 \mu \mathrm{m})$. (D) Hair with treatment of nanoemulsion $(2.0 \mu \mathrm{m})$. (E) Hair with treatment of nanoemulsion $(0.3 \mu \mathrm{m})$

Table 3 Deposition of silicone oil on hair

\begin{tabular}{llllll}
\hline Element & $\begin{array}{l}\text { Ratio (weight \%) } \\
\text { of hair without } \\
\text { treatment }\end{array}$ & $\begin{array}{l}\text { Ratio (weight \%) } \\
\text { of hair with } \\
\text { treatment of } \\
\text { shampoos }\end{array}$ & $\begin{array}{l}\text { Ratio (weight \%) } \\
\text { of hair with } \\
\text { treatment of } \\
\text { nanoemulsion }(\mathbf{4} \boldsymbol{\mu m})\end{array}$ & $\begin{array}{l}\text { Ratio (weight \%) } \\
\text { of hair with } \\
\text { treatment of } \\
\text { nanoemulsion }(\mathbf{2} \mu \mathrm{m})\end{array}$ & $\begin{array}{l}\text { Ratio (weight \%) } \\
\text { of hair with } \\
\text { treatment of } \\
\text { nanoemulsion }(\mathbf{0 . 3} \boldsymbol{\mu m})\end{array}$ \\
\hline Carbon & 50.72 & 51.93 & 51.92 & 51.90 & 54.00 \\
Nitrogen & 19.99 & 18.95 & 18.96 & 18.96 & 17.56 \\
Oxygen & 26.72 & 26.54 & 26.54 & 26.53 & 25.16 \\
Silicone & NA & 0.12 & 0.10 & 0.14 & 0.82 \\
\hline
\end{tabular}


Table 4 Effect of storage duration and temperature on silicone oil deposition on hair

\begin{tabular}{llllll}
\hline Element & $\begin{array}{l}\text { Ratio (weight \%) } \\
\text { of hair without } \\
\text { treatment }\end{array}$ & $\begin{array}{l}\text { Ratio (weight \%) } \\
\text { of hair with treatment } \\
\text { of shampoos } \\
\text { (after } \mathbf{4 0} \text { days at } \\
\text { room temperature) }\end{array}$ & $\begin{array}{l}\text { Ratio (weight \%) } \\
\text { of hair with treatment } \\
\text { of shampoos } \\
\text { (incubation at } \mathbf{4 0} \mathbf{\circ}^{\circ} \mathbf{C} \\
\text { for } \mathbf{4 0} \text { days) }\end{array}$ & $\begin{array}{l}\text { Ratio (weight \%) } \\
\text { of hair with treatment } \\
\text { of nanoemulsion }(\mathbf{0 . 3} \boldsymbol{\mu m} \text { ) } \\
\text { (at room temperature } \\
\text { after } \mathbf{4 0} \text { days) }\end{array}$ & $\begin{array}{l}\text { Ratio (weight \%) } \\
\text { of hair with treatment } \\
\text { of nanoemulsion } \\
(\mathbf{0 . 3} \boldsymbol{\mu m} \text { ) (incubation at } \\
\mathbf{4 0} \mathbf{C} \text { for } \mathbf{4 0} \text { days) }\end{array}$ \\
\hline Carbon & 50.72 & 51.94 & 51.95 & 54.00 & 54.01 \\
Nitrogen & 19.99 & 18.97 & 18.94 & 17.57 & 17.56 \\
Oxygen & 26.72 & 26.55 & 26.55 & 25.16 & 25.16 \\
Silicone & NA & 0.18 & 0.08 & 0.81 & 0.81 \\
\hline
\end{tabular}

The red region represents the homogeneous phase consisting of water, silicone oil, and emulsifier, which also stands for the condition of formed emulsion. For example, the composition of $0.675 \mathrm{~g}$ Span 80, $0.675 \mathrm{~g}$ Tween $80,0.45 \mathrm{~g}$ n-butanol, $0.2 \mathrm{~g}$ dimethyl silicone oil, and $1.5 \mathrm{~g}$ water is one of the optimal compositions of nanoemulsion, determined by observing the change of turbidity of the mixture (Table 1).

\section{Particle size and distribution of nanoemulsion}

The size and size distribution of nanoemulsion were determined using a laser particle analyzer (Mastersizer 2000; Malvern Instruments Ltd). As illustrated in Figure 3, the size distribution of nanoemulsion has two peaks: from $20 \mathrm{~nm}$ to $50 \mathrm{~nm}$ and from $100 \mathrm{~nm}$ to $700 \mathrm{~nm}$. However, the mean droplet size of nanoemulsions was found in the range of 100-705 nm.

\section{Stability of silicone oil nanoemulsion}

Unlike microemulsions that eventually produce phase separation, nanoemulsions formed at a particular concentration of oil, water, and surfactant are thermodynamically and physically stable systems. The formulations were tested for kinetic stability by centrifugation, and only the formulations that exhibited no phase separation or inversion, cracking, creaming, or coalescence upon these stress tests were selected for further storage stability studies. As can be seen in Figure 4, the nanoemulsions did not experience any physical changes after accelerated stability tests or storage, suggesting that they are suitable for delivering silicone oil on the hair surface.

The effect of size of nanoemulsion on its kinetic stability was also studied in terms of the changes in particle size and zeta potential. As shown in Table 2, the nanoemulsion stability enhanced as the nanoemulsion size decreased. This was possibly due to the increased zeta potential (Table 2) and viscosity as the nanoemulsion size dropped, impeding the coalescence of emulsion droplets. ${ }^{12-21}$

\section{Deposition of silicone oil on hair}

The deposition of silicone oil on hair following the treatment of nanoemulsion was investigated and compared with control groups by analyzing the elements in the hair (Figure 5 and Table 3). It was found that the deposition of silicone oil on hair was greatly enhanced by administering the nanoemulsion-containing shampoo. Moreover, as the nanoemulsion size decreased, the absorbed amount of nanodroplets on hairs increased because the sum of the nanoemulsions' weight fractions did not change. This can be explained by the fact that the smaller the nanoemulsion droplets the higher the interactions between them, leading to higher viscosity in the nanoemulsion and better silicone oil deposition. The results from the study on the effect of storage time and temperature on silicone oil deposition revealed that the amount of silicone absorption to the surface of hair did not change with the time and temperature, compared with the decreased absorption in control groups (Table 4). This could be caused by the instability of control group shampoos, which likely experienced phase separation during the extended storage duration and elevated storage temperature. ${ }^{12-21}$

\section{Conclusion}

In this study, thermodynamically stable nanoemulsions were successfully prepared and displayed improved silicone oil deposition on hair surface compared with traditional shampoos. The enhanced silicone oil deposition depends highly on the size of nanoemulsions. 


\section{Acknowledgments}

This research was supported by the Projects of National Science Foundation of China (Nos 81071025 and 81171203) and Projects of the Shanghai Committee of Science and Technology, China (Nos 11nm0503300, 11410708900, and 12XD1403800).

\section{Disclosure}

The authors report no conflicts of interest in this work.

\section{References}

1. Brown MA, Hutchins TA, Gamsky CJ, Wagner MS, Page SH, Marsh JM. Liquid crystal colloidal structures for increased silicone deposition efficiency on colour-treated hair. Int J Cosmet Sci. 2010;32(3):193-203.

2. Grabner D, Xin L, Hoffmann H, Drechsler M, Schneider O. The solubilisation of a water insoluble functionalized silicone oil in an aqueous surfactant solution: a novel mechanism for the solubilisation process. J Colloid Interface Sci. 2010;350(2):516-522.

3. Hossel P, Dieing R, Norenberg R, Pfau A. Sander R. Conditioning polymers in today's shampoo formulations - efficacy, mechanism and test methods. Int J Cosmet Sci. 2000;22(1):1-10.

4. Arzhavitina A, Steckel H. Foams for pharmaceutical and cosmetic application. Int J Pharm. 2010;394(1-2):1-17.

5. Yang $\mathrm{S}$, Yuan $\mathrm{W}$, Jin T. Formulating protein therapeutics into particulate forms. Expert Opin Drug Deliv. 2009;6(10):1123-1133.

6. Xu D, Hu Z, Su J, Wu F, Yuan W. Micro and Nanotechnology for Intracellular Delivery Therapy Protein. Nano-Micro Lett. 2012;4(2): $118-123$.

7. Yuan W, Wu F, Geng Y, Xu S, Jin, T. An effective approach to prepare uniform protein- $\mathrm{Zn}^{2+}$ nanoparticles under mild conditions. Nanotechnology. 2007;18(14):145601.

8. Yuan W, Zhang Y, Wu F, et al. Preparation of protein-loaded sustainedrelease microspheres via 'solid-in-oil-in-hydrophilic oil-in-ethanol (S/O/hO/E)' emulsification. Colloids Surf B Biointerfaces. 2010;79(2): 326-333.
9. Ren T, Yuan W, Zhao H, Jin T. Sustained-release polylactide-co-glycolide microspheres loaded with pre-formulated protein polysaccharide nanoparticles. Micro and Nano Lett. 2011;6(2):70-74.

10. Rong X, Mo X, Ren T, et al. Neuroprotective effect of erythropoietinloaded composite microspheres on retinal ganglion cells in rats. Eur $J$ Pharm Sci. 2011;43(4):334-342.

11. Yuan W, Hu Z, Su J, Wu F, Liu Z, Jin T. Preparation and characterization of recombinant human growth hormone- $\mathrm{Zn}{ }^{2+}$-dextran nanoparticles using aqueous phase-aqueous phase emulsion. Nanomedicine: Nanotechnology, Biology, and Medicine. 2012;8(4):424-427.

12. Chetty GN, Kamalam A, Thambiah AS. Acquired structural defects of the hair. Int J Dermatol. 1981;20(2):119-121.

13. Shaw DA. Hair lipid and surfactants. Extraction of lipid by surfactants and lack of effect of shampooing on rate of re-fatting of hair. Int $J$ Cosmet Sci. 1979;1(6):317-328.

14. Draelos ZD. Essentials of hair care often neglected: hair cleansing. Int J Trichology. 2010;2(1):24-29.

15. Egawa M, Hagihara M, Yanai M. Near-infrared imaging of water in human hair. Skin Res Technol. Epub June 4, 2012.

16. Wilgus LA, Davis K, Labeaud L, Gandolfi L. Lochhead RY. A study of the distribution of polymer/surfactant coacervate between solution and foam in archetypal shampoo systems. J Cosmet Sci. 2011;62(2): 179-189.

17. Watanabe S, Sato H, Shibuichi S, Okamoto M, Inoue S, Satoh N. Formation of nanostructure on hair surface: its characteristic optical properties and application to hair care products. J Cosmet Sci. 2007; 58(4):283-294.

18. Nagahara $Y$, Nishida $Y$, Isoda M, Yamagata $Y$, Nishikawa N, Takada K. Structure and performance of cationic assembly dispersed in amphoteric surfactants solution as a shampoo for hair damaged by coloring. J Oleo Sci. 2007;56(6):289-295.

19. Wood C, Sugiharto AB, Max E, Fery A. From conditioning shampoo to nanomechanics and haptics of human hair. J Cosmet Sci. 2011;62(2): 259-264.

20. Nazir H, Lv P, Wang L, Lian G, Zhu S, Ma G. Uniform-sized silicone oil microemulsions: preparation, investigation of stability and deposition on hair surface. J Colloid Interface Sci. 2011;364(1):56-64.

21. Trueb RM. Shampoos: ingredients, efficacy and adverse effects. J Dtsch Dermatol Ges. 2007;5(5):356-365.
International Journal of Nanomedicine

\section{Publish your work in this journal}

The International Journal of Nanomedicine is an international, peerreviewed journal focusing on the application of nanotechnology in diagnostics, therapeutics, and drug delivery systems throughout the biomedical field. This journal is indexed on PubMed Central, MedLine, CAS, SciSearch ${ }^{\circledR}$, Current Contents ${ }^{\circledR} /$ Clinical Medicine,

\section{Dovepress}

Journal Citation Reports/Science Edition, EMBase, Scopus and the Elsevier Bibliographic databases. The manuscript management system is completely online and includes a very quick and fair peer-review system, which is all easy to use. Visit http://www.dovepress.com/ testimonials.php to read real quotes from published authors. 